\title{
Inhibitory Effects of Alendronate on Adhesion and Viability of Preosteoblast Cells on Titanium Discs
}

\author{
Charukrit Lilakhunakon ${ }^{1} \quad$ jintamai Suwanpateeb ${ }^{2}$ Somying Patntirapong ${ }^{3}$ \\ ${ }^{1}$ Department of Implantology, Faculty of Dentistry, Thammasat \\ University, Pathum Thani, Thailand \\ 2Biofunctional Materials and Devices Research Group, National \\ Metal and Materials Technology Center, National Science and \\ Technology Development Agency, Pathum Thani, Thailand \\ ${ }^{3}$ Thammasat University Research Unit in Dental and Bone Substitute

\begin{abstract}
Address for correspondence Somying Patntirapong, DDS, DMSc, Thammasat University Research Unit in Dental and Bone Substitute Biomaterials, Faculty of Dentistry, Thammasat University, Rangsit campus 99 Moo 18 Pahonyothin Road, Klong Luang, Pathum Thani 12120 , Thailand

(e-mail: p_somying@hotmail.com; psomying@tu.ac.th).
\end{abstract} Biomaterials, Faculty of Dentistry, Thammasat University, Pathum Thani, Thailand

Eur J Dent 2021;15:502-508

\begin{abstract}
Objective This study aimed to investigate the effects of alendronate (ALN; a bisphosphonate) on adhesion and viability of preosteoblasts using different cell passages on sandblasted and acid-etched (SLA) Ti surfaces.

Materials and Methods Preosteoblast, MC3T3, cells (passage 42; P42 and passage 62; P62) were cultured with ALN (1 and $5 \mu \mathrm{M})$ on cell culture plate for 7 days. Cells were lifted, counted, and seeded on SLA Ti surfaces. Cells were incubated on the discs for 6 hours to examine cell adhesion by using confocal microscopy and for 24 hours to determine cell viability by using MTT assay.

Results ALN interfered with cell adhesion on Ti surfaces by reducing the cell number in both cell passages. Nuclei of untreated cells showed oval shape, whereas some nuclei of ALN-treated cells demonstrated crescent and condensed appearance. ALN at 1 and $5 \mu \mathrm{M}$ significantly decreased nuclear area and perimeter in P42, while ALN at

Keywords

- bisphosphonate

- implant

- osteoblast

- cell adhesion

- cell viability $5 \mu \mathrm{M}$ reduced nuclear area and perimeter in P62. After 24 hours, cells (P42) grown on Ti surfaces showed decreased cell viability when culturing with $5 \mu \mathrm{M}$ ALN.

Conclusion ALN reduced cell adhesion and viability of preosteoblasts on Ti surfaces. ALN treatment seemed to exert higher inhibitory effects on nuclear shape and size as well as cell viability in lower cell passage. This led to the reduction in cell to implant surface interaction after encountering bisphosphonate treatment.
\end{abstract}

\section{Introduction}

The rehabilitation with dental implants for replacing teeth has become more attractive and efficient than conventional fixed and/or removable prosthesis. The implants have been inserted in patients of all ages, especially in the elders. Patients receiving a drug called bisphosphonate may

published online June 7, 2021
DOI https://doi.org/

10.1055/s-0041-1726477

ISSN 1305-7456. also acquire dental implants for tooth replacement. Dental implant procedure is defined as dentoalveolar surgery, which can increase a risk of developing medication-related osteonecrosis of the jaw (MRONJ) in bisphosphonate-administered patients. ${ }^{1,2}$ Patients who obtain implant placement either during or after bisphosphonate treatment can accelerate the development of MRONJ. The occurrence ranges from 0 to

(C) 2021. European Journal of Dentistry.

This is an open access article published by Thieme under the terms of the Creative Commons Attribution-NonDerivative-NonCommercial-License, permitting copying and reproduction so long as the original work is given appropriate credit. Contents may not be used for commercial purposes, or adapted, remixed, transformed or built upon. (https://creativecommons.org/licenses/by-nc-nd/4.0/).

Thieme Medical and Scientific Publishers Pvt. Ltd. A-12, 2nd Floor, Sector 2, Noida-201301 UP, India 
66 months after implantation. ${ }^{2}$ However, survival rate of dental implant placement in patients receiving bisphosphonate is still controversy. ${ }^{3-7}$ Bisphosphonate administration reduces the survival rate of the implants to $86 \% 3$ and causes exposure of implant thread. ${ }^{8}$ The implant failure rate in patients taking bisphosphonate is estimated with a risk ratio of $1.73 .{ }^{4}$ On the contrary, several studies report that bisphosphonates do not have a negative impact on implant success rate..$^{5-7}$

Bisphosphonates have critical impact on bone remodeling process with the primary effect on osteoclasts. Other target cells include osteoblasts. ${ }^{9-11}$ Bisphosphonates affect osteoblast viability, differentiation, function, and gene expressions associated with differentiation such as Runx 2 and collagen type I. ${ }^{9-11}$ Osteoblasts play an important role in osseointegration by secreting collagen type I and subsequently deposition of hydroxyapatite to form the new bone around the dental implant. ${ }^{12}$ Bisphosphonates could interfere with new bone formation/bone healing around the implant by inhibiting osteoblast activities and may subsequently lead to failure of implant placement.

Many studies have reported the effects of bisphosphonates on osteoblast activities grown on cell culture plates as well as epithelial cell and gingival fibroblast adhesion on Ti surfaces. ${ }^{9-11,13}$ However, little is known about bisphosphonate-influenced adhesion and viability of osteoblasts on Ti surfaces. Since dental implant placement is not limited to a certain age, response of different cell passages to bisphosphonates might differ. Therefore, the purpose of this study was to investigate the effects of ALN on preosteoblast, MC3T3, adhesion, and viability on the implant surfaces at different passages. MC3T3 cells have been used as in vitro model for studying cell viability and the effects of senescence. ${ }^{14,15}$ According to Chung et al and Peterson et al, MC3T3 cells at passage less than 20 is considered early or low passage, passage 40 to 60 is high passage, and passage more than 60 is considered late or very high passage. ${ }^{15,16}$ This study utilized and modified by using passage 42 and 62 as middle-aged and old cells, respectively. This finding would gain the basic knowledge of the drug effects on cell adhesion and viability on Ti surfaces.

\section{Materials and Methods}

\section{Titanium Disc Preparation}

A $0.5-\mathrm{mm}$ thick commercially pure Ti grade 4 sheet was cut into $8 \mathrm{~mm}$ in diameter discs by using wire cutting machine (Sodick, AQ325L, Japan). Ti discs were blasted with aluminum oxide particles (size $50-270 \mu \mathrm{m}$ ) for 10 seconds. The distance from the tip of the blasting gun and the specimens was $90 \mathrm{~mm}$. The air pressure for sandblasting was set at $0.4 \mathrm{MPa}$. After sandblasting, specimens were immersed in $\mathrm{H}_{2} \mathrm{SO}_{4}-\mathrm{HCl}$ liquid $(45: 15 \% \mathrm{wt})$ for 10 minutes, sonicated in distilled water for 10 minutes, and then air dried. ${ }^{17}$ All specimens were sterilized by ethylene oxide gas. Prior to cell seeding on the Ti discs, the discs were immersed in the $\alpha$-minimum essential medium ( $\alpha$-MEM; Gibco, New York, United States) supplemented with $10 \%$ fetal bovine serum and $1 \%$ penicillin/streptomycin (standard media) overnight for protein adsorption onto the Ti surfaces.

Roughness of specimens was evaluated for the consistency of surface preparation. Three discs were randomly sampled for surface topography testing by using surface profiler (Surftest, Mitutoyo, United States). The degree of roughness of the substrate surfaces was processed with SURFPAK-SV software (version 1.300) and presented as arithmetical mean deviation of the assessed profile (Ra). Surface profile and the means Ra were shown in $\boldsymbol{- F i g . 1 A}$ and Table 1, respectively. The SLA surfaces of all discs tested had significantly higher roughness than the smooth surface, while there was no roughness difference among the SLA discs.

\section{Cell Culture and Treatments}

MC3T3 cells, mouse osteoblast precursors obtained from ATCC (CRL-2593) were cultured in standard media at $37^{\circ} \mathrm{C}$ and $5 \% \mathrm{CO}_{2}$. In this study, two cell passages were used: cell passage 42 to 44 and cell passage 62 to 64 . These passages were referred to $\mathrm{P} 42$ and P62, respectively. MC3T3 cells were first cultured at a density of 50,000 cells/well in six-well culture plates. Cells were treated with ALN at 1 and $5 \mu \mathrm{M}$ for 7 days. Untreated cells were served as control. After 7 days of treatment, MC3T3 cells were then trypsinized with $0.25 \%$ trypsin/EDTA. Cells were counted and 7,500 cells were

A

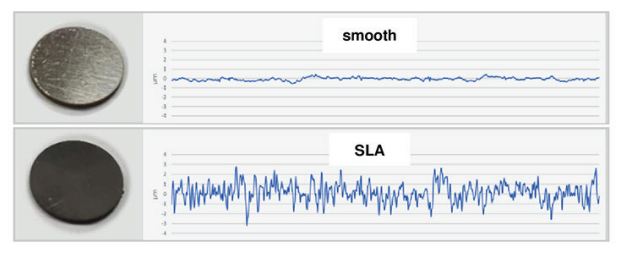

B

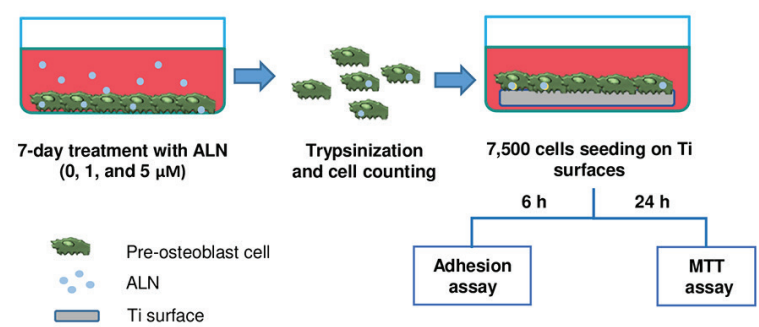

Fig. 1 (A) Surface profiles of Ti discs before (smooth; upper panel) and after sandblasting and acid etching (lower panel). (B) Diagram shows the experiment design of cell culture and testing assays.

Table 1 Surface roughness of smooth and sandblasted and acid-etched surfaces

\begin{tabular}{|l|l|l|}
\hline Surface & Roughness $(\mu \mathrm{m})$ & $p$-Value \\
\hline Smooth & $0.12 \pm 0.01$ & \\
\hline SLA1 & $0.69 \pm 0.06$ & $<0.01$ \\
\hline SLA2 & $0.73 \pm 0.02$ & $<0.01$ \\
\hline SLA3 & $0.76 \pm 0.03$ & $<0.01$ \\
\hline
\end{tabular}

Abbreviation: SLA, sandblasted and acid-etched.

Note: Values are expressed as mean Ra \pm standard deviation. 
seeded on each Ti disc. For cell adhesion and nuclear morphology assays, cells were incubated for 6 hours. For cell viability assay, cells were cultured for 24 hours.

\section{Cell Adhesion and Nuclear Morphology}

Cells were cultured as described in "cell culture and treatments." After seeding on Ti disc for 6 hours, nonadherent cells were removed by gently washing the discs with phosphate-buffered saline (PBS) solution. Cells were fixed with $4 \%$ paraformaldehyde for 15 minutes. Cells were permeabilized with $0.1 \%$ Triton-X-100 solution (Sigma-Aldrich, Missouri, United States) for 15 minutes. MC3T3 cells were thoroughly washed with PBS and stained with 4',6-diamidine-2-phenylindole dihydrochloride (DAPI; Sigma-Aldrich) at the dilution of 1:1,000 for 5 minutes for nuclear visualization. Cells were viewed under confocal microscopy (Nikon Eclipse Ti, Nikon Instruments). Images of nuclei were captured at $\times 200$ magnification by using NIS element AR 4.11.00 software. The number of nuclei is counted, which represented the number of cell adhesion on Ti discs. ImageJ software (National Institutes of Health version 1.8.0) was used for analyzing the nuclear projected area $\left(\mu \mathrm{m}^{2}\right)$ and nuclear perimeter $(\mu \mathrm{m})$.

\section{Cell Viability}

After seeding the cells on the discs for 1 day, MC3T3 cells were incubated with $0.2 \%$ (3-[4,5-dimethylthiazol-2-yl]-2,5-diph enyltetrazolium bromide) (MTT) solution (Sigma-Aldrich) at $37^{\circ} \mathrm{C}$ for 4 hours. The reaction was then stopped with dimethyl sulfoxide (Sigma-Aldrich) and glycine buffer (research organics). The formazan color was then analyzed by measuring the absorbance at $620 \mathrm{~nm}$ (A620) with Megellan software, V6.6.

\section{Statistical Analysis}

Data presented as means \pm standard deviation. Three independent experiments were conducted. To assess the drug effect at various concentrations, the mean values were compared by one-way ANOVA followed by Tukey's test. Significance was assigned as ${ }^{*} p<0.05$ and ${ }^{* *} p<0.01$.

\section{Results}

\section{Cell Adhesion}

To evaluate MC3T3 cell adhesion on Ti surface, confocal imaging of nuclei was assessed in three dimensions (xyz axis). DAPI-positive nuclei, representative of cells, were shown in blue color. In untreated control, adherent cells were seen throughout the surface of Ti discs. Blue nuclei were less confluent in ALN treatments in both P42 and P62, especially at higher concentration ( $5 \mu \mathrm{M}$; - Fig. 2A).

After 6 hours of cell seeding on Ti surface, approximately 13.5 and $14.5 \%$ of untreated cells adhered to the disc surfaces in P42 and P62, respectively (- Fig. 2B and 2C). ALN affected cell adhesion by decreasing the numbers of nuclei on Ti discs. Both concentrations of ALN (1-5 $\mu \mathrm{M})$ significantly reduced the number of cell adhesion when compared with control. The peak reduction was seen at $5 \mu \mathrm{M}$ ALN treatment. The numbers of adherent cells decreased up to
62 and 65\% in P42 and P62, respectively. However, there was no statistically significant difference between 1 and $5 \mu \mathrm{M}$ ALN groups ( - Fig. 2B and 2C).

\section{Nuclear Morphology and Size}

From two-dimensional fluorescence microscopy images, the morphology of DAPI-positive nuclei in untreated control cells were oval shape ( - Fig. $\mathbf{3 A}$ and $\mathbf{3 D}$ ). Some nuclei treated with ALN at $5 \mu \mathrm{M}$ appeared as condensed and crescent moon shapes as pointed with arrow heads and arrows, respectively (-Fig. 3C and 3F).

The average nuclear area of P42 control cells was $208 \mu \mathrm{m}^{2}$, whereas that of P62 was $163 \mu \mathrm{m}^{2}$. ALN at $5 \mu \mathrm{M}$ significantly decreased nuclear projected area on both P42 and P62 when compared with control group by 23 and $17 \%$, respectively. ALN at $1 \mu \mathrm{M}$ significantly reduced nuclear projected area over control by $18 \%$ only in P42. There were no significant differences between 1 and $5 \mu \mathrm{M}$ ALN on both P42 and P62 ( - Fig. 3G and $\mathbf{3 H}$ ). The average nuclear perimeter of $\mathrm{P} 42$ control cells was $53 \mu \mathrm{m}$, whereas that of P62 was $48 \mu \mathrm{m}$. The result in the nuclear perimeter had a similar trend as that in the average nuclear area. The peak reduction effect was found when treated cells with $5 \mu \mathrm{M}$ ALN ( - Fig. 3I and $\mathbf{3 J}$ ).

\section{Cell Viability}

MTT assay was used to examine cell viability of MC3T3 cells after 24-hour seeding on titanium discs, In P42, the lowest percentage of cell was found in $5 \mu \mathrm{M}$ ALN group. This concentration significantly reduced cell viability when compared with control. There was no statistical difference between control and $1 \mu \mathrm{M}$ ALN group ( - Fig. 4A). In P62, cells treated with $5 \mu \mathrm{M}$ ALN also displayed the lowest percentage of cell viability; however, no statistical difference was shown among control and experimental groups ( - Fig. 4B).

\section{Discussion}

Our study revealed the negative effects of ALN on preosteoblast adhesion, viability, and nuclear size on Ti surfaces. The concentrations used in this study were accounted for free bisphosphonate levels found in saliva or released from bone samples taken from patients with active MRONJ or receiving bisphosphonate. ${ }^{18}$ It has been shown that bisphosphonates interfere with adhesion in other cell types. Bone slices pretreated with ALN reduce the number of adherent osteoclast cells. ${ }^{19}$ Treatment with ALN at 0.5 to $5 \mu \mathrm{M}$ for 24 to 48 hours decreases epithelial and gingival fibroblast cell attachment on Ti discs by up to $30 \% \cdot{ }^{13}$ In this study, we found higher reduction of cell adhesion on Ti discs by up to $65 \%$. This could be due to the types of cell tested, experimental design, and the duration of treatment ( 7 vs. $1-2$ days).

ALN can cause positive or negative effects on osteoblast viability depending on the concentrations and treatment duration. ${ }^{10,20,21}$ A stimulating effect is seen at low concentrations of ALN ranging from 0.01 to $1 \mu \mathrm{M}$ on human osteoblast-like cells. ${ }^{20,21}$ On the contrary, the inhibitory effect of ALN is found at higher concentrations ( $>5 \mu \mathrm{M}$ ) on mouse primary osteoblast cells and human mesenchymal stem cells. ${ }^{9,10}$ The results 
A
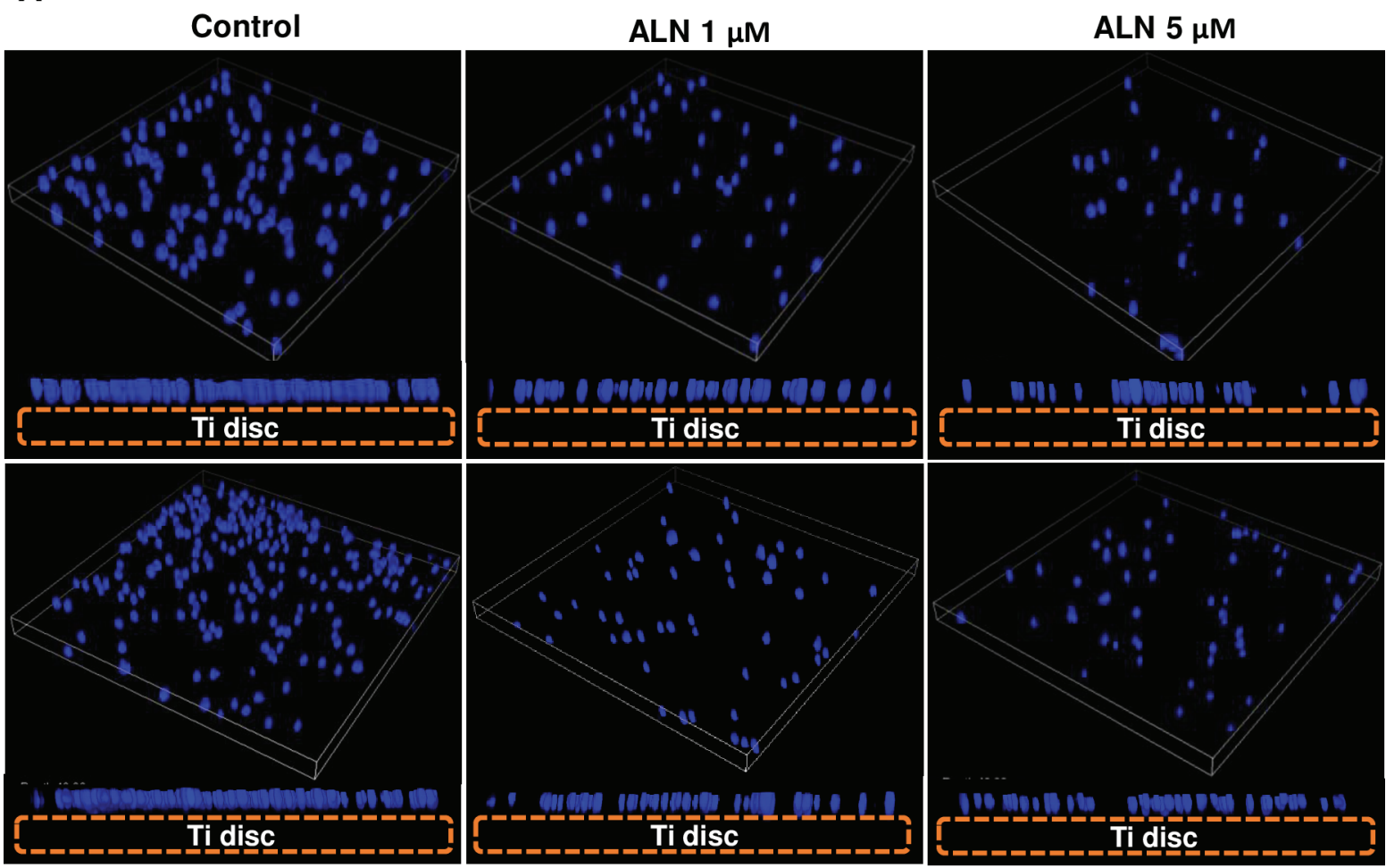

B

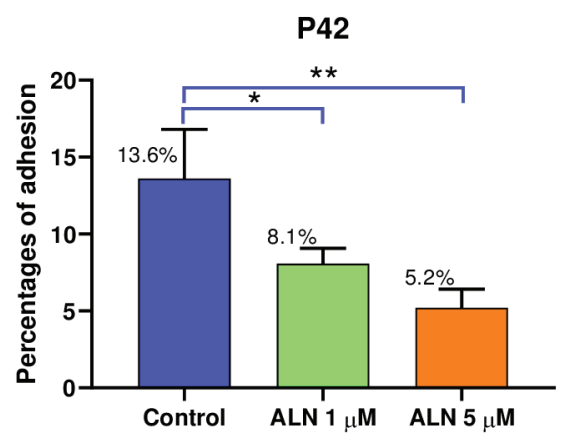

C

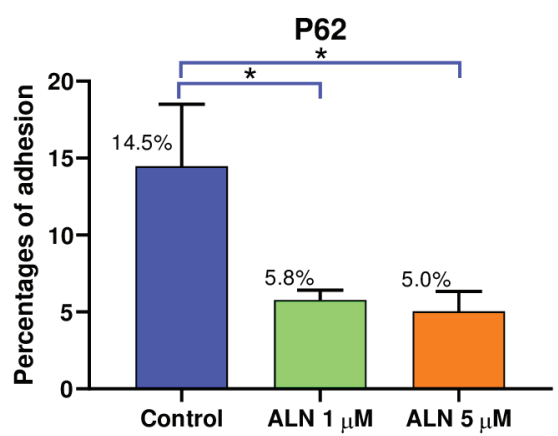

Fig. 2 Inhibition of preosteoblast adhesion on Ti surfaces after the treatment with alendronate. (A) DAPI-stained confocal imaging of MC3T3 cells, passage 42 (upper panel) and passage 62 (lower panel). (B) Percentages of cell adhesion, P42. (C) Percentages of cell adhesion, P62. Values are expressed as mean percentages \pm standard deviation; ${ }^{*} p<0.05$ and ${ }^{* *} p<0.01$ versus untreated control; $n=3$.

of this study showed no difference between cell viability of control and that of low-dose ALN treatment $(1 \mu \mathrm{M})$. The reduction of viable cells was observed only on cells treated with higher concentration of ALN $(5 \mu \mathrm{M})$, which is in an agreement with previous study by Patntirapong et al. ${ }^{10}$

The inhibition of osteoblast viability by bisphosphonates is reported primarily through the induction of cell apoptosis. ${ }^{9,11}$ One of the hallmarks of cell undergoing apoptosis is the characteristic changes in nuclear morphology. ${ }^{22-24}$ The early stage of nuclear change starts peripherally along the nuclear membrane, thus forming a crescent-like shape nucleus..$^{22}$ This is followed by nuclear condensation and fragmentation. ${ }^{22-24}$ The promotion of apoptosis can be detected by DAPI staining of the nuclei.9, ${ }^{923}$ Then, nuclear shape is monitored and nuclear size is measured. ${ }^{23,24}$ Cancer cells treated with cycloheximide, a potent activator of apoptosis, demonstrate nuclear shrinkage as shown by diminished nuclear area and perimeter. ${ }^{23}$ The changes in nuclear shape and area were observed after treatment with $5 \mu \mathrm{M}$ ALN. Some nuclei showed sign of early apoptosis (crescent shape), whereas some nuclei illustrated the later stage of apoptotic nucleus (a near spherical shape together with decreasing nuclear size). Furthermore, nuclear projected area data were in accordance with the trend of cell viability. This data support the notion that bisphosphonates cause cytotoxicity to osteoblasts, possibly through the initiation of apoptosis.,

ALN reduced cell adhesion, nuclear size, and cell viability in both passages in a similar trend. However, it was noticeable that the percentage of reduction was a little lower in higher passage except for the percentage of cell adhesion. Generally, cell activities begin to decline when cells age. In osteoblasts, cell activities decrease as passage number inc 

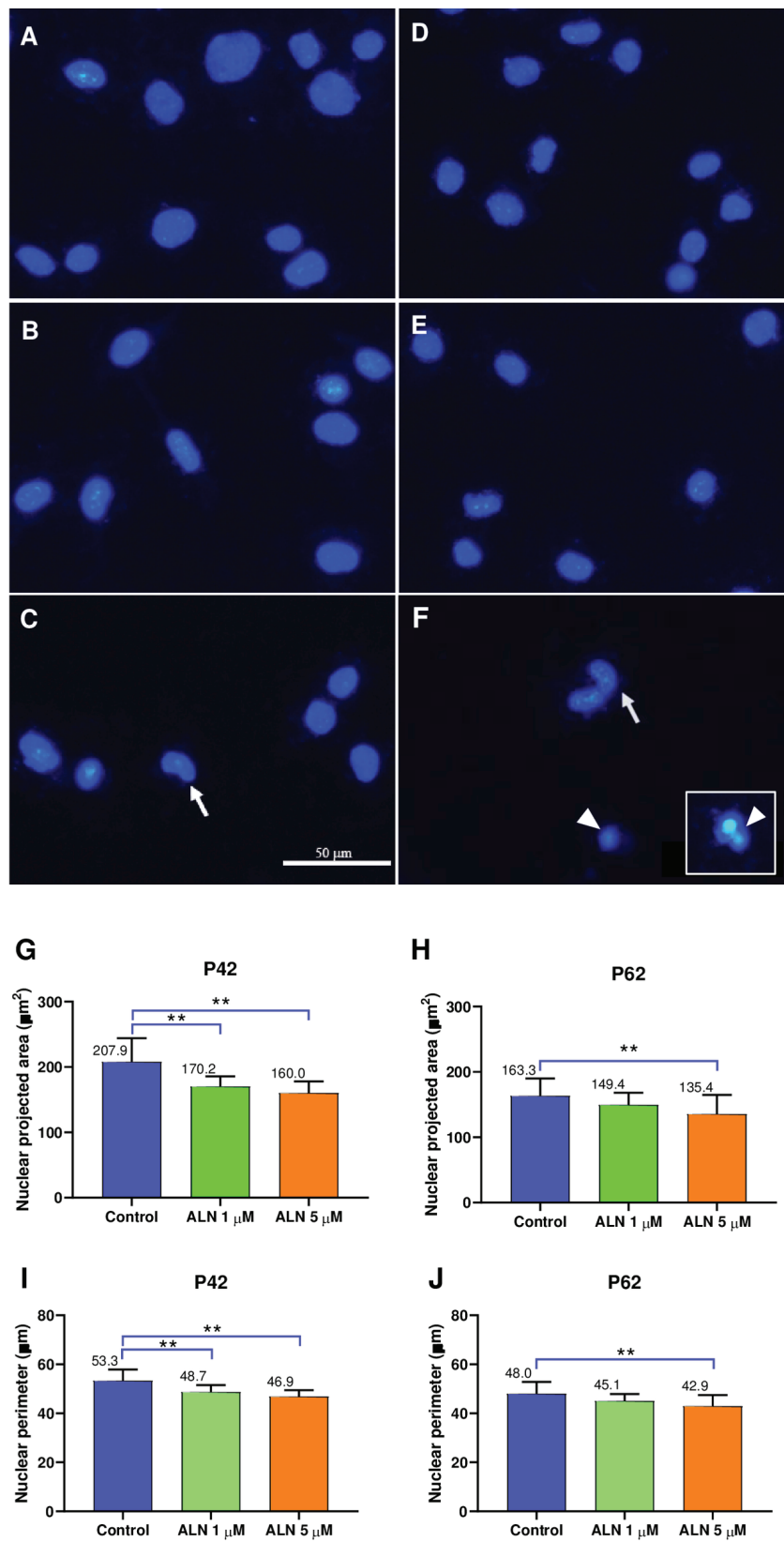

Fig. 3 Alteration of nuclear morphology and nuclear size of preosteoblasts after ALN treatment. Fluorescence microscopy images show DAPI-stained MC3T3 cells in two dimensions. (A) Control, P42. (B) ALN $1 \mu \mathrm{M}$, P42. (C) ALN $5 \mu \mathrm{M}$, P42. (D) Control, P62. (E) ALN $1 \mu \mathrm{M}$, P62. (F) ALN $5 \mu \mathrm{M}$, P62. White arrows label crescent nuclei and arrow heads label nuclear condensation. Inset demonstrates another view of nuclear condensation. Magnification at $\times 200$. (G) Nuclear projected area of cells at P42 $\left(\mu \mathrm{m}^{2}\right)$. (H) Nuclear projected area of cells at P62 $\left(\mu \mathrm{m}^{2}\right)$. (I) Nuclear perimeter of cells at P42 $(\mu \mathrm{m})$. (J) Nuclear perimeter of cells at P62 $(\mu \mathrm{m})$. Values are expressed as mean area/perimeter per field \pm standard deviation; ${ }^{* *} p<0.01$ versus untreated control; $n=$ 18. ALN, alendronate.

reases. ${ }^{16,25,26}$ Bisphosphonates are reported to be internalized into cells via endocystosis. ${ }^{27}$ This cellular process is decreased in aging cells or senescent cells. ${ }^{28}$ It could be possible that higher passage cells altered in cell response to the drug treatment by internalizing less ALN. However, this speculation needs to be investigated in the future. In addition, the limitation of this study was that only two passages were employed,
A

P42

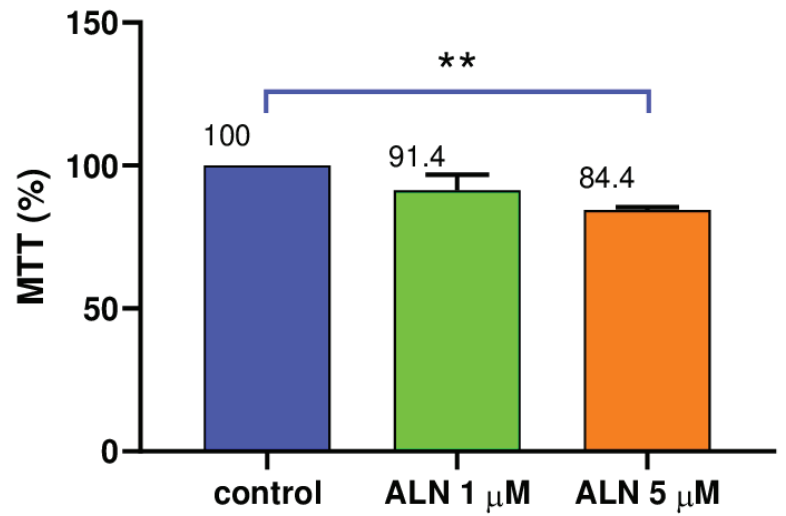

B

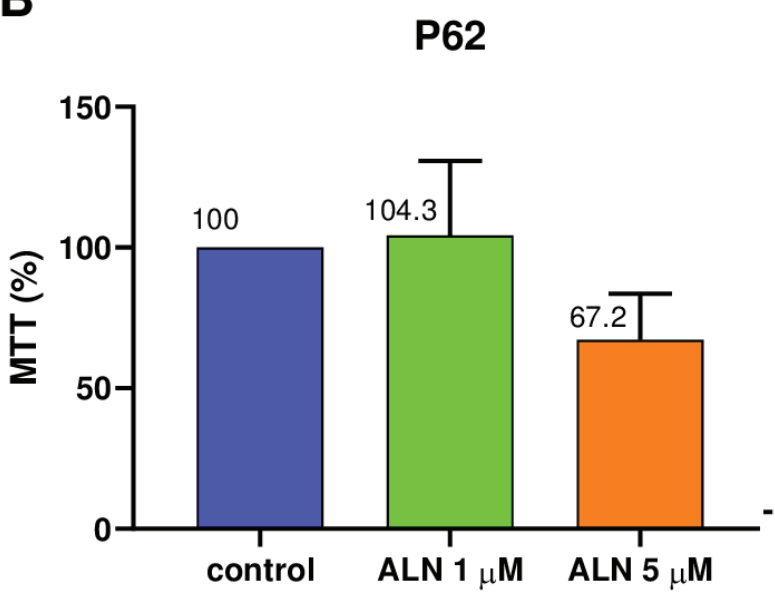

Fig. 4 Reduction of cell viability grown on Ti discs by alendronate. Cell viability were examined by MTT assay after seeding for 24 hours. (A) P42. (B) P62. Values are expressed as mean percentages \pm standard deviation; ${ }^{* *} p<0.01$ versus untreated control; $n=3$.

and the data might not represent the whole range of other passages.

An implant insertion creates a wound in bone tissue. Naturally, bone tissue regenerates around the implant, thus generating a firm anchoring of an implant. The key factors of bone/Ti implant interaction requires good cell health including cell attachment and viability. Bone surface provides a population of osteogenic cells, while the implant surface relies upon the recruitment and migration of the osteogenic cells. Later on, new bone formation develops on the implant surface (contact osteogenesis), which finally joins with bone formation forming on the host bone (distant osteogenesis; -Fig. 5A). In bone microenvironment treated with bisphosphonates, osteogenic cells expose to the drug. Uptake of ALN negatively affected osteogenic cells/Ti implant interaction by reducing cell adhesion to the implant surface and cell viability, thus interfering with the interaction process of bone/implant ( $\boldsymbol{- \text { Fig. }}$. 5B). It should be noted that the results of in vitro study with bisphosphonates might not be relevant to in vivo occurrence. The data should be interpreted with caution. Patients treated with oral 
A

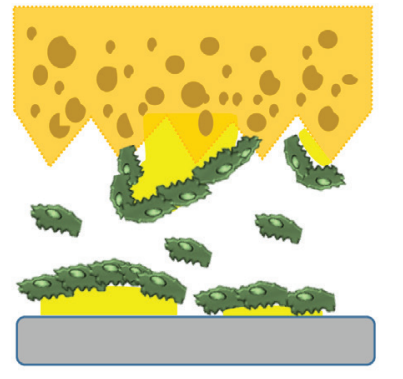

B
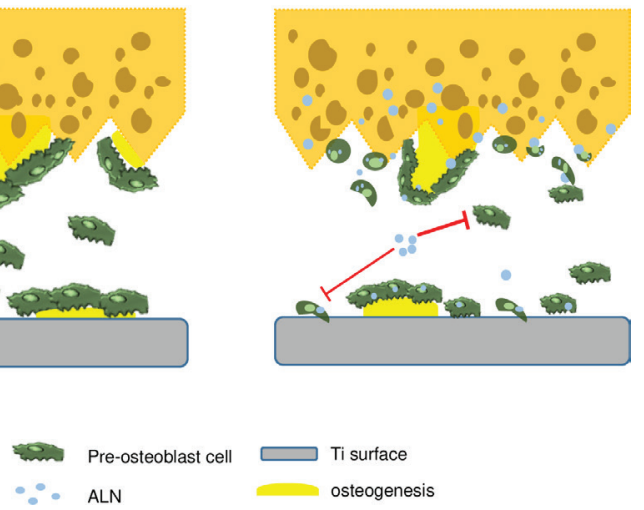

Fig. 5 A proposed schematic diagram of effects of ALN on preosteoblast adhesion and viability. (A) ALN-free bone microenvironment. (B) ALN-treated bone microenvironment. ALN, alendronate.

bisphosphonates appeared to have good results for implant placement. ${ }^{7}$ However, failure of implant as well as the risk of developing MRONJ still exists. ${ }^{2,29}$ Patients treated with bisphosphonate should be considered with precautions when undergoing implant surgery. ${ }^{7,29}$

\section{Conclusion}

This study revealed negative effects of ALN on preosteoblast viability by the induction of cell apoptosis. ALN also interfered cell adhesion on Ti surfaces. Both cell passages were affected by the drug. The data demonstrated the role of bisphosphonate on bone cell/implant interaction. This should raise awareness when considering an implant placement.

\section{Funding}

The funding for this study was granted by Thammasat University Research Fund under the TU Research Scholar grant (grant id. 77/2561).

\section{Conflict of Interest}

None declared.

\section{Acknowledgment}

The authors gratefully acknowledge Thammasat University Research Fund under the TU Research Scholar grant for partial support of this work.

\section{References}

1 Ruggiero SL, Dodson TB, Fantasia J, et al; American Association of Oral and Maxillofacial Surgeons. American Association of Oral and Maxillofacial Surgeons position paper on medication-related osteonecrosis of the jaw-2014 update. J Oral Maxillofac Surg 2014;72(10):1938-1956

2 Holzinger D, Seemann R, Matoni N, Ewers R, Millesi W, Wutzl A. Effect of dental implants on bisphosphonate-related osteonecrosis of the jaws. J Oral Maxillofac Surg 2014;72(10):1937. e1-1937.e8

3 Kasai T, Pogrel MA, Hossaini M. The prognosis for dental implants placed in patients taking oral bisphosphonates. J Calif Dent Assoc 2009;37(1):39-42
4 Chrcanovic BR, Albrektsson T, Wennerberg A. Bisphosphonates and dental implants: a meta-analysis. Quintessence Int 2016;47(4):329-342

5 Ata-Ali J, Ata-Ali F, Peñarrocha-Oltra D, Galindo-Moreno P. What is the impact of bisphosphonate therapy upon dental implant survival? A systematic review and meta-analysis. Clin Oral Implants Res 2016;27(2):e38-e46

6 Koka S, Babu NM, Norell A. Survival of dental implants in post-menopausal bisphosphonate users. J Prosthodont Res 2010;54(3):108-111

7 Gelazius R, Poskevicius L, Sakavicius D, Grimuta V, Juodzbalys G. Dental implant placement in patients on bisphosphonate therapy: a systematic review. J Oral Maxillofac Res 2018;9(3):e2

8 Zahid TM, Wang BY, Cohen RE. Influence of bisphosphonates on alveolar bone loss around osseointegrated implants. J Oral Implantol 2011;37(3):335-346

9 Idris AI, Rojas J, Greig IR, Van't Hof RJ, Ralston SH. Amino-bisphosphonates cause osteoblast apoptosis and inhibit bone nodule formation in vitro. Calcif Tissue Int 2008;82(3):191-201

10 Patntirapong S, Singhatanadgit W, Arphavasin S. Alendronateinduced atypical bone fracture: evidence that the drug inhibits osteogenesis. J Clin Pharm Ther 2014;39(4):349-353

11 Patntirapong S, Singhatanadgit W, Chanruangvanit C, Lavanrattanakul K, Satravaha Y. Zoledronic acid suppresses mineralization through direct cytotoxicity and osteoblast differentiation inhibition. J Oral Pathol Med 2012;41(9):713-720

12 von Wilmowsky C, Moest T, Nkenke E, Stelzle F, Schlegel KA. Implants in bone: part I. A current overview about tissue response, surface modifications and future perspectives. Oral Maxillofac Surg 2014;18(3):243-257

13 Basso FG, Pansani TN, Soares DG. Cardoso LM, Hebling J, de Souza Costa CA. Influence of bisphosphonates on the adherence and metabolism of epithelial cells and gingival fibroblasts to titanium surfaces. Clin Oral Investig 2018;22(2):893-900

14 Vajrabhaya LO, Korsuwannawong S, Surarit R. Cytotoxic and the proliferative effect of cuttlefish bone on MC3T3-E1 osteoblast cell line. Eur J Dent 2017;11(4):503-507

15 Peterson WJ, Tachiki KH, Yamaguchi DT. Serial passage of MC3T3-E1 cells down-regulates proliferation during osteogenesis in vitro. Cell Prolif 2004;37(5):325-336

16 Chung CY, Iida-Klein A, Wyatt LE, et al. Serial passage of MC3T3-E1 cells alters osteoblastic function and responsiveness to transforming growth factor-beta1 and bone morphogenetic protein-2. Biochem Biophys Res Commun 1999;265(1):246-251

17 Taira Y, Egoshi T, Kamada K, Sawase T. Surface modification with alumina blasting and $\mathrm{H} 2 \mathrm{SO} 4-\mathrm{HCl}$ etching for bonding two resin-composite veneers to titanium. Eur J Oral Sci 2014;122(1):84-88

18 Scheper MA, Badros A, Salama AR, et al. A novel bioassay model to determine clinically significant bisphosphonate levels. Support Care Cancer 2009;17(12):1553-1557

19 Colucci S, Minielli V, Zambonin G, et al. Alendronate reduces adhesion of human osteoclast-like cells to bone and bone protein-coated surfaces. Calcif Tissue Int 1998;63(3):230-235

20 Im GI, Qureshi SA, Kenney J, Rubash HE, Shanbhag AS. Osteoblast proliferation and maturation by bisphosphonates. Biomaterials 2004;25(18):4105-4115

21 Xiong Y, Yang HJ, Feng J, Shi ZL, Wu LD. Effects of alendronate on the proliferation and osteogenic differentiation of MG-63 cells. J Int Med Res 2009;37(2):407-416

22 Ziegler U, Groscurth P. Morphological features of cell death. News Physiol Sci 2004;19:124-128

23 Mandelkow R, Gümbel D, Ahrend H, et al. Detection and quantification of nuclear morphology changes in apoptotic cells by 
Lilakhunakon et al.

fluorescence microscopy and subsequent analysis of visualized fluorescent signals. Anticancer Res 2017;37(5):2239-2244

24 Filippi-Chiela EC, Oliveira MM, Jurkovski B, Callegari-Jacques SM, da Silva VD, Lenz G. Nuclear morphometric analysis (NMA): screening of senescence, apoptosis and nuclear irregularities. PLoS One 2012;7(8):e42522

25 Kwist K, Bridges WC, Burg KJ. The effect of cell passage number on osteogenic and adipogenic characteristics of D1 cells. Cytotechnology 2016;68(4):1661-1667

26 Kassem M, Ankersen L, Eriksen EF, Clark BF, Rattan SI. Demonstration of cellular aging and senescence in serially passaged long-term cultures of human trabecular osteoblasts. Osteoporos Int 1997;7(6):514-524
27 Thompson K, Rogers MJ, Coxon FP, Crockett JC. Cytosolic entry of bisphosphonate drugs requires acidification of vesicles after fluid-phase endocytosis. Mol Pharmacol 2006;69(5):1624-1632

28 Foroozandeh P, Aziz AA, Mahmoudi M. Effect of cell age on uptake and toxicity of nanoparticles: the overlooked factor at the nanobio interface. ACS Appl Mater Interfaces 2019;11(43):39672-39687

29 de-Freitas NR, Lima LB, de-Moura MB, Veloso-Guedes CC, Simamoto-Júnior PC, de-Magalhães D. Bisphosphonate treatment and dental implants: a systematic review. Med Oral Patol Oral Cir Bucal 2016;21(5):e644-e651 